\title{
Elevated blood lithium concentration following concomitant lithium and propranolol therapy: A case report
}

\author{
Emine Füsun Akyüz Çim $^{1^{*}}$ and Hülya Çeçen ${ }^{2}$ \\ ${ }^{1} V$ an District Training and Research Hospital Department of Psychiatry, Van, Turkey \\ ${ }^{2}$ Tatvan State Hospital Department of Psychiatry, Bitlis, Turkey
}

\begin{abstract}
Lithium is used in the treatment for many psychiatric disorders, like bipolar disorder, schizoaffective disorder and depression. Lithium has a very narrow therapeutic range and there are many reasons that increase the blood levels of lithium. Combining lithium with other medications with the aim of reducing side effects or supporting the therapy may result in substantial elevations in lithium concentrations and may lead to signs of intoxication.

This study presents increased blood lithium concentration after the initiation of the concomitant therapy of lithium and propranolol, which is a beta-blocker drug, due to the complaint of tremor causing functional impairment.
\end{abstract}

Key Words: Lithium, beta-blocker, propranolol, drug interactions

\section{Introduction}

Lithium is used in the treatment for many psychiatric disorders, like bipolar disorder, schizoaffective disorder and depression. Lithium is absorbed by gastrointestinal tract. Afterwards absorbing lithium is distributed in extracellular fluid initially. In principally kidneys eliminates lithium.

Lithium has a very narrow therapeutic range and there are many reasons that increase the blood levels of lithium. Combining lithium with other medications with the aim of reducing side effects or supporting the therapy may result in substantial elevations in lithium concentrations and may lead to signs of intoxication. Interaction of lithium with several nonsteroidal anti-inflammatory drugs (NSAIDs), thiazide diuretics, and angiotensinconverting enzyme (ACE) inhibitors have been commonly reported. Additionally, diabetes insipidus, low salt diet, over 50 years old, hypothyroidism and deterioration in renal function could be risk factors for lithium intoxication (1).

With lithium treatment side effects in many organ systems could be seen. One of them is neurological system. Neurotoxic side-effects such as nystagmus, ataxia, tremor, fasciculation, clonus, seizure and even coma have been well described in the literature. Tremor is the most common neurological side effect caused by the use of lithium (2).

Different treatment options are available for the treatment of tremor related to lithium, such as reduction of lithium dose, addition of beta blocker. For Lithium-induced tremor treatment, in one of the most frequently used $\beta$-blocker agent is propranolol. Because of the presentation of tremor, we added propranolol to the lithium therapy. Propronolol is non selective sympatholytic beta blocker with a hepatic elimination. Also, propronolol is the drug that is not expected to interact with lithium.

In this study, we present a patient who had been on lithium therapy for the last one year due to the diagnosis of bipolar disorder and was presented with increased blood lithium concentration after the initiation of the concomitant therapy of lithium and propranolol, which is a beta-blocker drug, due to the complaint of tremor causing functional impairment.

\section{Case report}

A 32-year-old male patient had been followed up due to the diagnosis of bipolar disorder for the 
last 9 years. He was married, unemployed, had three children. He lived with his family in a small town very near to city center. For daily activity, he could help child care, do shopping, occasionally deal with gardening. He had good self-care and sociability. Last one year, he had come to the regular monthly psychiatric out patients clinic for follow-up.

The patient had been treated by various physicians with numerous pharmacotherapeutic agents and had been receiving a monotherapy with lithium $1200 \mathrm{mg} /$ day for the last one year. Patient history revealed that the patient had several manic episodes due to the reduction or cessation of drug use over the last one year. He came to psychiatric polyclinic with his brother. In the psychiatric physical exam; he was oriented to place, time and person. No delusion was described. His speech was organized and his mood was euthymic.

Biochemical analysis revealed a blood lithium level of $0.76 \mathrm{mEq} / \mathrm{L}$. The patient was present with tremor that caused functional impairment in both hands, which was also detected during the physical examination. Also, no neurotoxic side-effects such as nystagmus, ataxia, fasciculation were definied but tremor. Due to the presentation of tremor, propranolol was added to the lithium therapy in a divided dosage of $40 \mathrm{mg} /$ day. Two weeks later, the patient presented to the polyclinic with the complaints of dizziness, nausea, exhaustion, and weakness. The blood lithium level was elevated to $1.6 \mathrm{mEq} /$ Lit. No pathology was detected in electrocardiography (ECG). Laboratory tests revealed that hemogram, blood biochemical parameters (glucose, urea, creatinine, AST, and ALT), thyroid hormone levels, and parathyroid hormone levels were in normal range. Serum electrolyte levels were determined as: Sodium: 137 mmol/L, Potassium: $3.7 \mathrm{mmol} / \mathrm{L}$, Magnesium: 1.9 $\mathrm{mEq} / \mathrm{L}$, Phosphate: $1.1 \mathrm{mmol} / \mathrm{L}$.

Considering the risk of drug interaction, the propranolol therapy was terminated and the blood lithium levels were followed up every other day. All the symptoms were completely removed within the first week and the blood lithium level progressively decreased to $0.78 \mathrm{mEq} / \mathrm{L}$ in 10 days.

\section{Discussion}

Tremor is the most common neurological side effect caused by the use of lithium (2). In patients with side effects such as tremor, if reduction or cessation of the use of lithium is not considered, a beta-blocker drug such as propranolol should be added to the lithium therapy. In our patient, since the patient had a history of several manic episodes, we did not reduce the dosage of lithium due to the risk of repeated manic episodes and added propranolol with the lithium therapy. Second week of combined lithium and propranolol treatment, neurotoxic signs was defined related with lithium blood level rising. Increase in blood levels of lithium in our case occurred independently from the oral lithium dose intake. This shows that, a problem which relating to renal excretion of lithium could be. Reduction of excretion of lithium could be due to two reasons; the kidney function is damaged or another drug that affect renal excretion is used.

Chemical tests showed that the physiological limits of the parameters such as kidney function tests that could lead to rising of lithium blood level. The rise in the blood level of lithium in clinical evaluation was linked to possible drug interactions between lithium and propranolol.

A large part of the lithium is excreted through the kidneys (3). Lithium is filtered through the kidney glomeruli and absorbed back from proximal tubules. Approximately $80 \%$ of the lithium filtered is reabsorbed by the glomerulus and the remainder is excreted as urine (4). Increased intake or decreased excretion from kidney is responsible of lithium toxicity (5).

Nonsteroidal anti-inflammatory drugs (NSAIDs), thiazide diuretics, and angiotensin-converting enzyme (ACE) inhibitors are the drugs which could changed lithium dosage. Also, diabetes insipidus, low salt diet, being over 50 years old and deterioration in renal function could be risk factors for lithium intoxication (1). As seen, the common features, drugs and situations which change lithium serum levels are effective on kidney cell and ion.

In our case possible mechanisms which may cause high blood lithium levels are:

-Changes in the concentration of sodium ions

-Lithium and propranolol's effect on the renin angiotensin aldosterone system

-Lithium and propranolol on the cell signaling system.

Lithium blood levels could be changed by sodium ion concentration. The most sensitive to lithiuminduced alterations is renal collecting tubule .Lithium is reabsorbed into the collecting duct cells from sodium channel. Also, lithium is used like sodium in proximal tubules (4). Lithium reduce water and salt reabsorption. Therefore possible changes on ion sodium levels may affect the de lithium serum levels. 
Another structure on the kidney, that can lead to potential changes for lithium and sodium ion is Renin-Angiotensin-Aldosterone-System (RAAS). In the kidney juxtaglomerular cells secrete renin, when blood pressure falls and the sodium chloride reaching the cell juxtaglomerular level falls. The enzyme renin stimulates angiotensin complex. End of circulation the hormone system, aldosterone is released from adrenal kortex. Aldosterone increases water and sodium retention in blood.

A possible explanation may be drug interactions at the molecular level intracellular cell signaling system. Lithium and propranolol is effective on adenylate cyclase $(6,7)$. Effect of the drugs (lithium and propranolol) on adenylate cyclase activities could bring interactions together.

In our case we have added propranolol for the treatment of tremor induced lithium which is non selective sympatholytic beta blocker propranolol, commonly used in the treatment of lithiuminduced tremor. Although, propranolol is highly extracted in the liver (8), propranolol has effects on glomerular filtration and the enzyme of renin. Propranolol's effect on the kidneys could bring the lithium blood level changes possible. Propranolol inhibits renin release on kidney like other beta blocker drugs (9).

With prevention of renin enzyme, aldosteron blood level decreases. So that, sodium ion concentration in water volume could decrease too. As a result; the inhibited renin enzyme by propronolol could changed lithium serum level because of the decreasing of sodium concentration and water volume.

Another factor may affect on blood levels of lithium is glomerular filtration. Removing excess wastes and fluids is the processes by glomerular filtration. Glomerular filtration is the first stage for excretion of lithium from the body by kidney. Propranolol could cause lowering effect on glomerular filtration (10), so that lithium blood levels may increase by glomerular filtration reduction.

Additionally, propranolol and lithium are effective on adenylate cyclase activities. cAMP is a second messenger, used for intracellular signal transduction and is synthesized from ATP by adenylate cyclase and involved in the regulation of certain renal function such as the provision of the normal fluid balance.

Lithium is effective on neurotransmitter pathways and gene expression. Transferring genetic information pathway of cAMP is the main target for intracellular effects of lithium. cAMP is suppressed on many cell types including kidney epithelial cells by lithium (6). On the other hand the effects of propranolol on the cAMP pathway are in inhibitory features (7).

As shown, likewise both drugs (propranolol and lithium) may make adenylate cyclase inhibition. For these two drugs with the same mechanism on intracellular signal transduction system may occur with the possible drug interactions.

In conclusion, Propranolol is a sympatholytic agent with a hepatic elimination and is not likely to interact with lithium. In our patient, the blood lithium level was elevated, likely because of the concomitant lithium and propranolol therapy. Hypothetically, the elevation in lithium concentration may be associated with the lowering effect of propranolol on glomerular filtration, inhibiting renin release on kidney by propranolol, the interaction of lithium and propranolol with the adenylate cyclase activities, or an unknown drug interaction. The case presented in this study indicates that concomitant lithium and propranolol therapy may lead to toxic levels of lithium concentration in blood. The clinicians should be awakened about this possible drug interactions.

\section{References}

1. Shine B, McKnight RF, Leaver L, Geddes JR. Long-term effects of lithium on renal, thyroid, and parathyroid function: a retrospective analysis of laboratory data. Lancet 2015; 386 : 461-468.

2. Morgan JC, Sethi KD. Drug-induced tremors. Lancet Neurol 2005; 4: 866-876.

3. Timmer RT, Sands JM. Lityum intoxication. J Am Soc Nephrol 1999; 10: 666-674.

4. Psikiyatride Güncel Yaklaşımlar-Current Approaches in Psychiatry 2011; 3(3):426-445 (C) 2011, eISSN:1309-0674 pISSN:1309-0658.

5. Aral H, Vecchio-Sadus A. Toxicity of lithium to humans and the environment- A literature review. Ecotoxicol Environ Saf 2008; 70: 349356.

6. Lenox RH, McNamara RK, Papke RL, Manji HK. Neurobiology of lithium: An update. J Clin Psychiatry 1998; 58: 37-47.

7. Conley D, Coyne M, Chung A, Bonorris G, Schoenfield L. Propranolol inhibits adenylate cyclase and secretion stimulated by deoxycholic acid in the rabbit colon. Gastroenterology 1976; 71: 72-75.

8. Shand DG. Pharmacokinetics of propranolol: a review. Postgrad Med J 1976; 52: 22-25.

9. Laragh JH, Bühler FR. Propranolol, renin and hypertension: a review. Postgrad Med J 1976; 52: 109-115.

10. Bahalı K, Gülçelik G, Fettahoğlu Ç, et al. (Çev). Duygudurum Düzenleyiciler. Avc1 A, Yolga

East J Med Volume:23, Number:2, April-June/2018 
Tahiroğlu A (Çev Edit.). Çocuk ve ergenlerde psikotropik ilaç kullanımı \& Klinik El Kitabı.
Bezchlıbnyk KZ, Viranı BAS (eds). Adana Nobel Kitabevi, Adana, 2010. s: 198-230.

East J Med Volume:23, Number:2, April-June/2018 